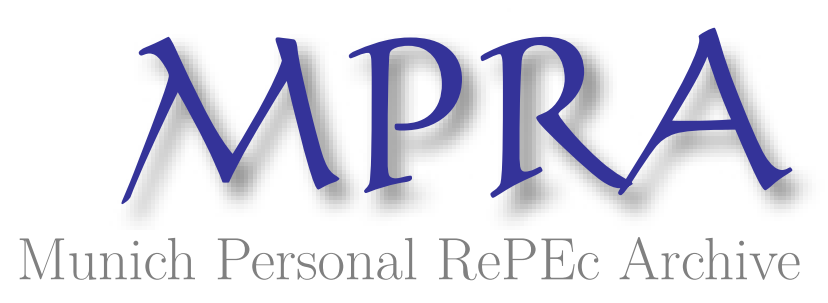

\title{
The Historical Perspective of the Problem of Interpersonal Comparisons of Utility
}

Drakopoulos, Stavros A.

University of Glasgow

1989

Online at https://mpra.ub.uni-muenchen.de/28996/

MPRA Paper No. 28996, posted 22 Feb 2011 21:01 UTC 


\title{
The Historical Perspective of the Problem of Interpersonal Comparisons of Utility ${ }^{1}$
}

\author{
BY \\ STAVROS DRAKOPOULOS \\ January 1989 \\ UNIVERSITY OF GLASGOW
}

\begin{abstract}
The starting-point of the article is the inconsistency between the established practice of acceptance in many cases, of economic policy (i.e. progressive taxation, national insurance policies) and the theoretical rejection of interpersonal comparisons of utility who see it as an unscientific value judgement. The inconsistency is explained by identifying three groups of theorists: (1) those who thought of comparability as a value judgement and unacceptable for economic policy considerations (positivists), (2) those who agreed with the positivists, on the normative nature of comparability but accepted it as a basis for economic policy, and (3) those who thought of it as part of a scientific economics. The implication was that, despite the dominance of positivist methodology in other sub-fields, the historical experience points to the difficulty of applying positivist methodology to the issue of comparability. If the inconsistency is thus due to the inappropriateness of the positivist approach, the only possible solution is the explicit abandonment of this approach at least in matters related to the collective aspects of economics.
\end{abstract}

Keywords: History of Economics, Welfare Economics

JEL Codes: B0, D6

${ }^{1}$ This article has benefited from comments from Professor Brian Loasby, Dr Sheila Dow, and Ron Shone 


\section{Introduction}

The issue of interpersonal comparisons of utility is about the possibility (or not) of comparing the utility or welfare or the mental states in general of different individuals. Before we go on, it would be useful to mention that a number of economists have used different terms from that of utility. Some of the terms that have been used are: ophelimity, happiness, satisfaction, pleasure, economic welfare, enjoyment. All of these terms were conceived as subjective sensations. Thus by the concept of interpersonal comparisons we will mean the comparison of subjective sensations in general (for the use of other concepts and their relationship to utility, see Wicksteed, 1933, pp. 417-18; Pareto, 1971, p. 112; Pigou, 1951, p. 289, and Tarascio, 1979, p. 411). It can be maintained that interpersonal comparison is an important problem in economics. Its importance can be realised from the fact that almost every major economist in the history of economics has devoted some space to the discussion of the issue. In the last 70 years, the discussion of comparability has intensified and has become more controversial. The controversy was centred on the possibilities or impossibility of interpersonal comparisons. Although there is still evidence of the continuation of the discussion, one can state that the majority of economists are prepared to declare that interpersonal comparisons are not possible. As Sen points out: "the use of interpersonal comparisons is widely thought to be arbitrary, and many people view these comparisons as meaningless" (Sen, 1970, p. 4). Or as one can read in the influential Henderson and Quandt's

\section{Microeconomic Theory:}

Welfare comparisons would be simple if it were possible to aggregate the utilities of individuals into a single function. Unfortunately, this operation cannot be performed. Interpersonal comparisons of utility are not possible (Henderson and Quandt, 1971, p. 255).

Most of the economists who rejected comparability rejected it on the basis that it is a value judgement. This idea is a product of the influence of positivist scientific philosophies in economics. In particular, Robbins was the one who promoted it in the modern period, and thus influenced the views of contemporary economists. However, despite' this explicit rejection of comparability by the majority of economists, interpersonal comparisons are implicitly assumed in many cases.

A few indicative examples will clarify the above. First, the welfare concept of real national income, which is so popular among economists and social scientists in 
general, presupposes comparability. (It must be mentioned that the productive capacity concept does not require comparability.) Usher has pointed out that the welfare-based concept of real income which is widely used involves interpersonal comparisons of utility (Usher, 1980, pp. 57-61). One might also note that the significance of national income as a welfare indicator among different countries requires some means of aggregating individual welfare which in turn implies comparability. Secondly, the theoretical justification of the system of progressive taxation rests on the assumption that comparability is possible.

Apart from the above theoretical cases, interpersonal comparisons are also assumed in a significant number of policy measures. For instance, the national insurance systems of many countries tend to favour certain parts of the population. Again this implies comparability. In addition, the adoption of progressive taxation by a large number of countries is further evidence of acceptance of comparability in matters of economic and social policy.

The contemporary dominant view of the impossibility of comparability and the above mentioned examples present a serious inconsistency. The roots of this inconsistency can be traced back into the history of ideas of major economists about comparability. One can distinguish two streams of thought: the utilitarian oriented economists with a belief in comparability and cardinal measurability of utility, and the advocates of positive economics who deny comparability and favour ordinal utility. The fact that the majority of contemporary economists reject comparability indicates that the winners of this long controversy were the positivists. However, the implicit acceptance of comparability, as discussed above, signifies that the utilitarian oriented economists had their influence too.

In this article, an attempt will be made to explain this inconsistency by discussing the emergence and the development of the above broadly defined two streams of economic thought. Moreover, the evolution of policy measures which require comparability will be discussed, and an attempt to connect it with the theoretical developments will be made. In addition, the more recent discussions of the issue of comparability, especially in the context of welfare economics will be examined. 


\section{Bentham and Mill}

The origin of utilitarianism can be found in the ideas of Bentham. The cornerstone of Bentham's system was the "Greatest Happiness Principle", which sets the moral standard for the individual and for the community. In Bentham's words: ' 'It is the greatest happiness of the greatest number that is the measure of right and wrong" (Bentham, 1969, p. 45). This principle inevitably demands that utility be measurable and Bentham attempted to measure it according to its duration, intensity, certainty, etc. (Bentham, 1969, pp. 96-7). For Bentham, the community's total utility is the sum of individual utilities, and his ideal is the collective maximisation of happiness which clearly implies the possibility of comparability. In his other major work, Theory of Legislation, the acceptance of comparability is more explicit. Two propositions are stated: (a) "of two individuals with unequal fortunes, he who has the more wealth has the more happiness"; (b) "the excess happiness of the richer will not be so great as the excess of his wealth" (Bentham, 1882, p. 103). Proposition (a) compares feelings among individuals and proposition (b) implies both diminishing marginal utility for each individual and similar capacities for satisfaction. These two last ideas are also basic for subsequent utilitarian economists. Moreover, Bentham's justification of proposition (a) provides an additional explicit acceptance of comparability. As he writes, "a king's happiness would be greater than the average happiness of a thousand farmers" (Bentham, 1882, pp. 104-5).

In general the very nature of Bentham's system involves comparability. It is a key concept for the application and the logical coherence of his philosophy. Utilitarianism started as mainly a social philosophy. Social objectives and questions play a central role. Along with comparability, measurability of utility is also important. However, Bentham accepted comparability without giving adequate justification. It seems that he considered it as obvious to everyone. As we shall see, the subsequent economists who accepted comparability and cardinal measurability belong to the utilitarian tradition. Utilitarianism and comparability of utility are vitally connected.

Mill was the first major classical economist to be influenced by Bentham. 
Following Bentham, Mill emphasises the importance of the Greatest Happiness Principle as a universal moral standard. Mill stresses that the principle refers to the maximisation of happiness of the society not of the individual: "[It] is not the agent's own greatest happiness, but the greatest amount of happiness altogether" (Mill, 1979, p. 262). His emphasis on the collective maximisation of happiness implies his conviction that the community's total utility is the sum of individual utilities which in turn involves comparability. Again, like Bentham, he believed in the measurability of pleasure or utility (Mill, 1979, pp. 262-4). In addition, Mill makes explicit interpersonal comparisons in his discussion of the Greatest Happiness Principle.

That principle [Greatest Happiness Principle] is a mere form of words without rational signification, unless one person's happiness, supposed equal in degree (with the proper allowance made for kind) is counted for exactly as much as another (Mill, 1979, p. 319).

It can be said that the above passage signifies the essence of Mill's utilitarianism: apart from comparability, equal capacity for pleasure for every individual is also accepted. The emphasis by Mill on the second idea can be attributed to his being a liberal utilitarian. Collective maximisation and equal value to everybody are essential in his thought.

Thus, with Bentham and Mill, the utilitarian tradition in-economics starts to take shape. In short, utilitarianism put much emphasis on social questions and its solution to these questions, collective maximisation of happiness, inevitably involved the certainty of making interpersonal comparisons.

\section{Marginalist School}

As observed above, comparability is an issue which arises in theories which mostly deal with social questions (utilitarianism). The first three founders of the Marginalist School do not mention much about the issue. Their relative indifference towards comparability can be explained by their tendency to be interested mainly in analysing microeconomic phenomena. This is why we find explicit reference to comparability in only one of the three founders of marginalism. More specifically, only Jevons refers to it in his Theory of Political Economy and he rejects it. His justification for the rejection was based not so much on positivist grounds (although positive elements can be found in his work) as would be the case with subsequent economists, but on the 
difficulty of finding any means for making interpersonal comparisons (Jevons, 1871, p. 21). It seems that the Austrian, Menger, the least marginalist of the three, wanted to avoid discussing the subject. A possible explanation for this can be his emphasis on subjectivity. It would be difficult to expect Menger to hold that an independent observer can compare the individual (subjective) utilities of different persons. In addition, Menger's position can be related to the reluctance of the Austrian economists to make predictions of other people's behaviour. In general, Austrian economists are not interested in welfare economics. Walras also avoided the issue although he made some incidental interpersonal comparisons (Stigler, 1950, p. 318). We believe that his preference towards microeconomic study was a central reason for the above avoidance

However, one can find explicit reference to comparability in the works of economists of the second marginalist generation (end of 19th/beginning of 20th centuries) who were more inclined towards social questions in economics. In addition, the second generation further developed the theory of utility and one of the consequences of this development was the more systematic discussion of the problem of interpersonal comparisons. Apart from those two factors, another important reason for the interest in the issue of comparability was the first steps by national governments towards legislating income taxation. In particular, in the latter half of the 19th century the UK and US governments made the first moves towards establishing income taxation. Thus, the need for the theoretical justification of progressive taxation added to interest in comparability because without comparability progressive taxation cannot be justified theoretically. Moreover, the influence of the utilitarian thought (the Greatest Happiness Principle) on the emergence of the above measures must be taken into account.

\section{$\underline{\text { Marshall }}$}

In contrast with the founders of marginalism, Marshall showed a considerable interest in social questions and matters of economic policy. Thus, in his work Marshall refers to the problem of comparability explicitly. First of all, in many parts and appendices of his Principles of Economics utility is treated as a cardinal concept (Marshall, 1961, pp. 93, 838). This cardinality facilitates the acceptance of comparability which Marshall was eager to endorse in the first editions of his 
Principles. In the subsequent editions (especially in the ninth) he was less eager but still convinced. Thus, one can read the following indicative passage in the last edition:

[ T] he real worth of a thing might be discussed with reference not to a single person but to people in general, and thus it would naturally be assumed that a shilling's worth of gratification to one Englishman might be taken as equivalent with a shilling's worth to another, "to start with "and "until cause to the contrary were shown": but everyone would know that this was a reasonable course only on the supposition that the consumers of tea and those of salt belonged to the same classes of people, and involved people at every variety of temperament. This involves the consideration that a pound's worth of satisfaction to an ordinary poor man is a much greater thing than a pound's worth of satisfaction to an ordinary rich man (Marshall, 1961, p. 130).

It can be observed that for Marshall comparability is possible only when people belong to the same class. The same idea can be found in subsequent economists who discuss comparability. Moreover, Marshall's statement, that a pound has a greater utility (or gives more satisfaction) to the poor man than it gives to the rich man, was to become the basis for the theoretical justification of progressive taxation. Marshall's acceptance of comparability was in line with his cardinal conception of utility and also with his willingness to discuss the solutions of social issues through economics. Thus, as far as the issue of comparability is concerned, Marshall's ideas belong to the utilitarian framework.

\section{Edgeworth}

Edgeworth's economic thought was probably much closer to utilitarianism than Marshall's. The calculus of pleasure and pain is the basis of economics for Edgeworth. More specifically, he distinguishes between economical and utilitarian or moral calculus. The economical calculus "investigates the equilibrium of a system of hedonic forces each tending to maximum individual utility"; while the utilitarian calculus investigates "the equilibrium of a system in which each and all tend to maximum universal utility" (Edgeworth, 1881, p. 15). Although he recognises some difficulties in the measurability of utility or pleasure, Edgeworth proceeds to invent a unit which measures pleasure. This unit which has two dimensions, time and intensity, is adequate for economical calculus. However:

For moral calculus a further dimension is required; to compare the happiness of one person with the happiness of another, and generally the happiness of groups of different members and different average happiness (Edgeworth 1881, p. 7).

Edgeworth's utilitarian or moral calculus is close to the contemporary idea of the 
maximisation of social welfare and, by pointing out the need for comparability in this issue, he follows the utilitarian tradition. Moreover, he is prepared to justify theoretically his belief in comparability. As he writes:

Such comparisons can no longer be shirked if there is to be any systematic morality at all. It is postulated by distributive justice. It is postulated by the population question (Edgeworth, 1881, p. 8).

However, contrary to the utilitarian framework — and especially to Bentham and Mill - Edgeworth does not accept equal capacities for satisfaction. He holds that some people have greater capacity for happiness than others (Edgeworth, 1881, p. 57). Edgeworth's departure at this point prevents him from concluding that equal distribution leads to an increase of total welfare (even if he admits - as he doesdiminishing marginal utility of income). Also this is the main reason for his rejection of the idea of progressive taxation (see also Creedy, 1981, pp. 89-91). However, in his later work, Papers Relating to Political Economy, he finds comparability necessary for establishing a theory of taxation.

Practically, I think, in order to apply A2 - to show for instance that the richer class should contribute a larger sum of money (I do not say a larger proportion of income) - we must presuppose the sympathetic comparison of wants and feelings experienced by different persons. (Edgeworth, 1925, p. 235).

Thus, Edgeworth reinforced the utilitarian idea that problems of social welfare involve interpersonal comparisons. Moreover, he was one of the first economists to draw attention to the issue of taxation and to state explicitly that comparability is needed for its solution.

\section{Pareto}

It can be maintained that Pareto's ideas on comparability mark the emergence of the positivist approach. More specifically, Pareto's ideas were the representative example of the application of positivist thought in economics. As a positivist, he advocated the rejection of all metaphysical or ethical concepts from social sciences (especially from Economics and Sociology). Thus, not without justification, a great number of contemporary welfare economists consider Pareto to be the founder of positive welfare economics. The main reasons for this were first Pareto's attempt to get away from the controversial notion of the cardinal measurability of utility and to replace it with the concept of ordinal preference; and, secondly, Pareto's endeavour to find a social optimum position without the necessity of comparing 
the satisfactions of different persons. Pareto's indices of ophelimity set the basis for the subsequent theory of choice which claims to be independent of any subjective concepts and assumptions. (For a discussion of the concept of ophelimity and its relationship with utility, see Hutchinson, 1960, p. 220; and Cooter and Rappoport, 1984, p. 515.) However, from our point of view the key here is his idea that interpersonal comparisons of utilities or ophelimities have no scientific basis:

The ophelimity, or its index, for one individual, and the ophelimity, or its index, for another individual, are heterogeneous quantities, We can neither add them together nor compare them. No bridge, as the English say. A sum of ophelimity enjoyed by different individuals does not exist; it is an expression which has no meaning (Pareto, 1971, p. 172).

The assertion that comparability is meaningless can be found in subsequent positivist oriented economists who would see it as the main justification for the rejection of interpersonal comparisons

However, it must be noted that Pareto is not very strict in following his rejection of comparability. In some parts of his work he seems to be tolerant of the idea. More specifically, in his Cours d'Economie Politique he is prepared to admit comparison of utilities - he uses it as a more general term - among peoples: "If we admit, as it is done generally enough, that utility, for a people, is mixed with the material prospering and the moral and intellectual development, we have a criterion to establish comparisons among different peoples" (Pareto, 1896, p. 51). In his Manual he is more specific. He states that there are two classes of theories. Intrapersonal comparisons belong to the first class; interpersonal comparisons to the second class. According to him the study of the theories of the second class is the most unsatisfactory in social science (Pareto, 1971, p. 106). However, he realises the need for theories of the second class (comparability) in his discussion of equilibrium in a collectivist society especially in the problem of distribution. In order to proceed in his discussion, Pareto assumes that the problem of comparability is solved (Pareto, 1971, p. 267). The important point here is that, although he denies comparability in principle, he is prepared to accept it in matters of collective welfare. Thus we can state that in the second generation of the marginalist school, the utilitarian tradition continues in the ideas of Marshall and Edgeworth about comparability. However, with Pareto, we have the systematic introduction of the positivist approach towards the issue which was to become 
so influential in the subsequent discussion (see Aron, 1967, p. 145). Before closing this section, it is useful to mention that Wicksell and Fisher, who also belong to the second marginalist generation, pointed to the need for comparability in social questions (Wicksell, 1961, p. 76 and Fisher, 1927, p. 159).

\section{Post-marginalist Developments}

\section{$\underline{\text { Utilitarian Welfare Economics }}$}

In the previous section it was observed that economists of the second generation of the marginalist school emphasised explicitly that interpersonal comparisons were necessary for problems related to aggregate welfare. During the first decades of the 20th century, there was a considerable increase of interest in these problems of social welfare. Moreover, during the same period, there was the legislation for progressive taxation by UK and USA which added further interest in the issue of comparability (Blum and Kalven, 1953, p. 12). Also, the National Insurance Act of 1911 can be seen in the above perspective.

The result of this increased interest in social welfare was the emergence of a separate field of economics: welfare economics, with the publication of Pigou's book, Wealth and Welfare, in 1911. Naturally, the requirement of comparability was one of the bases for the new sub-field. Pigou followed the strict utilitarian approach and he made interpersonal comparisons:

Nevertheless it is evident that any transference of income from a relatively rich man to a relatively poor man of similar temperament, since it enables more intense wants to be satisfied at the expense of less intense wants, must increase the aggregate sum of satisfaction (Pigou, 1939, p. 87).

The idea of "similar temperament" is very close to Marshall's and Fisher's views. Moreover, Pigou's statement that equal distribution increases welfare is valid here only when one assumes (apart from comparability) measurability of utility, diminishing marginal utility and equal capacities for satisfaction. Pigou thought of the above as factual assumptions. This statement is in accordance with the views of Bentham, Mill and Marshall. Pigou himself realises the implicit assumptions of his statement when he writes:

The old "law of diminishing utility" thus leads securely to the proposition: "Any cause which increases the absolute share of real income in the hands of the poor, provided that it does not 
lead to a contraction of the national dividend from any point of view, will in general increase economic welfare" (Pigou, 1932, p. 87).

In general, Pigou, like Bentham, conceives of social welfare as the sum of individual welfares and thus, as we have seen, implies the comparability of utilities or welfare of different individuals. Pigou uses the concept of economic welfare which is very similar to the concept of satisfaction (see Pigou, 1951, p. 288). However, it must be noted that, in spite of his acceptance of comparability, Pigou had reservations about the accuracy of interpersonal comparisons. It seems that comparability was one of his still empty economic boxes.

Harrod's ideas about comparability belong to the Pigovian tradition. In his presidential address before Section F of the British Association (1938), Harrod agreed with Pigou about comparability. Moreover, like Pigou, he accepted the diminishing marginal utility of income and the equality of capacities for satisfaction.

The further postulate that the two pence has lower utility to a millionaire than the $£ 25$ p.a. man is based on some sort of assumption about equality of men in regard to their needs which must not be pressed too far. But so also do the prescriptions favourable to free markets. For the individuals who gain by the opening of a market are often different from those who suffer some loss. Consider the Repeal of the Corn Laws. This tended to reduce the value of a specific factor of production - land. It can no doubt be shown that the gain to the community as a whole exceeded the loss to the landlords - but only if individuals are treated in some sense as equal (Harrod, 1938, p. 396).

Harrod's example of an increase of the social gain with the Repeal of the Corn Laws presupposes comparability of utilities. Finally, Harrod - like most of the economists that were discussed in the previous pages - finds comparability absolutely necessary for welfare questions and generally for welfare economists (Harrod, 1938, p. 397).

Thus, it can be maintained that the utilitarian tradition, which continued in the welfare economics of Pigou and Harrod, was dominant in the first decades of this century. The theoretical acceptance of interpersonal comparisons was matched with economic and social policy developments like the adoption of progressive taxation and of national insurance: developments which clearly presupposed comparability. 


\section{The Growth of Positivist Framework}

Logical Positivism was a scientific philosophy which emerged at the beginning of this century. Its basis can be found in 19th century positivism. The fundamental point of this system was that a statement, which cannot be verified or which is not a tautology, is meaningless. In particular, these meaningless statements are branded "value judgements". As one of the founders of logical positivism put it: "Value judgements have no theoretical sense. Therefore we assign them to the realm of metaphysics" (Carnap, 1981, p. 150). The influence of logical positivism on economics was considerable. Although Robbins cannot be branded a logical positivist, he was one of the first economists to be influenced by this philosophical movement. Robbins represented the introduction of the spirit of logical positivism in economics which rejected any non-verifiable (non-scientific) element in social sciences. Robbins' thought was in a way connected with the earlier positivist ideas of Pareto discussed above.

The implications of the spirit of logical positivism for the issue of comparability and for welfare economics in general were very important. More analytically, the most important argument against comparability was that it was conceived as a value judgement and thus meaningless. Thus, comparability was rejected as a nonscientific statement. In Robbins' words:

I still cannot believe that it is helpful to speak as if interpersonal comparisons of utility rest upon scientific foundations - that is, upon observation and introspection (Robbins, 1938, p. $640)$.

Robbins' assertion that introspection is a legitimate scientific method is very interesting because it has two important implications. The first one which is crucial for comparability is that introspection might be seen as a potential basis for interpersonal comparisons. The second one is the problematic character of intersubjective agreement about economic data once introspection is accepted. Moreover, apart from the above, Hutchison has pointed out the logical contradiction between adopting intrapersonal comparisons of utility as a legitimate basis of the theory of consumer behaviour and at the same time rejecting comparability as a basis of welfare economics (see Hutchison, 1965, p. 138). Robbins' rejection of comparability as a value judgement was to have substantial influence on subsequent economists. Robbins also rejected the idea of equal capacities for 
satisfaction on the same grounds. Before we proceed, it has to be mentioned that, although Robbins rejected comparability in principle, he was ready to accept it in matters of economic policy so long as its normative character was stated explicitly (see Robbins, 1938, pp. 640-1).

Robbins' rejection of comparability is also connected with his views about the measurability of utility. More specifically, during this period the established view of a cardinally measurable utility started to be challenged by the idea of ordinal utility. As we have seen, all the previous economists (with the exception of Pareto) thought of utility as cardinally measurable. The impact of logical positivism was again present in the theory of ordinal utility. In particular, the ambiguity of the utility concept and even more the ambiguity of a cardinal utility concept led positivist oriented economists to the invention of ordinal utility (see Hicks and Allen, 1934). The important point here is that cardinal utility facilitates interpersonal comparisons and thus, with its rejection, the theoretical justification of comparability weakened to a great extent.

Finally, Robbins' statement in his earlier and very influential work, An Essay of the Nature and Significance of Economic Science, that comparability cannot be justified by appeal to any kind of positive science, constitutes the corner-stone of the positivist framework (Robbins, 1969, pp. 140-1).

Robbins's views on interpersonal comparisons of utility marked an important stage in the history of the development of the concept. Since then, theorists have been divided over the subject. One can identify three groups broadly defined:

(1) Those who accept Robbins' argument that interpersonal comparisons have no scientific basis insist that policy recommendations should be purely scientific, and restrict their recommendations accordingly. It is clear that this group represents a strict positivist position.

(2) Those who accept Robbins' arguments, but contrast "positive", scientific economics, from which interpersonal comparisons are banished, with economic policy, in which science may legitimately be combined with value judgements, or ethics. 
(3) Those who believe that interpersonal comparisons have scientific basis and are willing to integrate them into a scientific framework. One can argue that the third group is closer to the utilitarian position.

\section{First Group}

The first group's views on comparability were very influential during the years after the publication of Robbins' critique of the scientific standing of interpersonal comparisons. The great influence of this strict positivist approach meant that Pigovian welfare economics was left without a solid basis.

Thus, a need for a new approach to welfare economics arose. The basic characteristic of the New Welfare economics was the exclusion of interpersonal comparisons. The idea was that, by the rejection of comparability, they tried to avoid the "normative" or non-scientific characterisation of welfare economics. The main representatives of the new approach were Kaldor, Hicks and Lange. In order to construct a welfare theory without making interpersonal comparisons, Kaldor and Hicks attempted to establish a new welfare criterion. This criterion (Kaldor-Hicks criterion) states that the economist can say that a certain policy increases the aggregate real income when "it is quite sufficient for him to show that, even if all those who suffer as a result are fully compensated for their loss, the rest of the community will still be better off than before" (Kaldor, 1939, p. 550). However, it must be noted that the Kaldor-Hicks criterion avoids comparability only if the compensation is actually paid and accepted by the loser as full and fair since it is the loser who is the only one capable of assessing the magnitude of the loss (economists have pointed out, however, that the Kaldor-Hicks criterion still assumes implicit comparability (see, for instance, Koutsoyiannis, 1979, p. 529). Lange defines total welfare as a vector which has to be maximised subject to the condition that no person's utility is decreased.

The common feature of the new welfare school is the idea of comparability as a value judgement. Most of the members criticise Pigovian welfare economics because it accepts comparability (see, for instance, Hicks, 1939, p. 697). The main problem according to them was the non-scientific character of interpersonal comparisons. Lange, for instance, held that the whole problem was the utilitarian 
idea that the total welfare of the community was the sum of individual utilities which implies comparability of utilities (Lange, 1942, p. 215). Thus, the positivist criticism of utilitarian welfare economics became very strong in the writings of the above mentioned theorists.

\section{$\underline{\text { Social Welfare Functions and Arrow's Theorem }}$}

The idea of social welfare functions represented the attempt to construct "meaningful" (in the logical positivist context) welfare theory which will be able to give prescriptions in policy questions. The first social welfare function was proposed by Bergson who, following the positivist framework, thought that Marshall's and Pigou's conception of aggregate welfare involved comparability which is a value judgement (Bergson, 1938, p. 310). Bergson believed that, with his social welfare function, he would be able to overcome the problem of comparability. More specifically, he defines it as a function of the welfare of each member of the community, or of the quantities of goods and services consumed by each member. In symbols (the function is ordinally defined):

$W=W\left(U^{1} U^{2}, U^{3} \ldots U^{n}\right)$

$W=$ economic welfare, $n=$ individual, and $U$ - individual utility. The idea is to maximise the above function, subject to a production function:

$\mathrm{Q}=f(K, L)$

In his Foundations of Economic Analysis, Samuelson stated a similar social welfare function of the general form (it is ordinally defined and $z$ represents all possible variables):

$W=W\left(z_{1} z_{2}, \ldots\right)$

The above has to be maximised subject to the constraint, the general form of which can be written as:

$g i\left(z_{1} z_{2}, \ldots\right)=0$

Samuelson admits that the exclusion of comparability from the assumptions of 
the welfare function limits the range of welfare economics. However, he points out that it can "assure us that there exists a still better point if we are at a point on the Possibility function" (Samuelson, 1947, pp. 203-53).

Thus, it seemed that the concept of social welfare can give life again to the field of welfare economics. The Kaldor-Hicks criterion and the Bergson-Samuelson social welfare function represented the positivist attempt to rebuild welfare economics.

However, Arrow's impossibility theorem showed that the concept of social welfare function is vulnerable to criticism. More specifically, in 1951, Arrow in his work, Social Choice and Individual Values, wrote:

If we exclude the possibility of interpersonal comparisons of utility, then the only methods of passing from individual tastes to social preferences which will be satisfactory and which will be defined for a wide range of sets of individual orderings are either imposed or dictatorial (Arrow, 1963, p. 59).

The important point was that he showed the impossibility of deriving a nondictatorial social welfare function. In essence, Arrow's theorem undermined the attempts to construct a positivist welfare economics. The positivist-inspired rejection of comparability left us without an acceptable welfare theory, or at least limited, to a great extent, the policy suggestions of the positivist oriented economists.

The positivist approach towards comparability was dominant in the first decades after the Second World War, and thus the position that comparability is a value judgement and so not acceptable in economics was shared by the majority of economists. However, many economists began to realise the serious limitations that the rejection of comparability imposed on matters of policy suggestions. More specifically, in the first post-war years, a huge increase of the state sector took place in many countries. This meant the introduction of macro policies and of welfare policies, like national insurance, in the principal western countries. In particular, in the UK the National Health Service and National Insurance Acts were introduced 
in 1946. These measures were the products of the Beveridge report of 1942.

Analogous measures were taken by other national governments. Moreover, the system of progressive taxation became more widespread in a great number of countries. It can be said that these measures were based on the ideas of utilitarian welfare economics. All of the above measures required that interpersonal comparisons are possible. Thus, it was clear that there was an inconsistency between the established practice and the rejection of comparability by mainstream economics.

The result was that the positivist approach started to lose influence among economists and especially among welfare economics theorists. Signs of modification of the strict positivist position appeared and this brings us to the second and third groups.

\section{Second Group}

Robbins can be seen as a forerunner of this group since he was prepared to accept comparability in matters of economic policy given that it was explicitly conceived as a value-judgement (non-scientific). Scitovsky was one of the first economists to emphasise the difficulties emerging from a strict positivist position and also the need for comparability in policy prescriptions. The following quotation from his 1951 article is indicative of the approach of the second group:

Strictly speaking, such an assumption [comparability] is not objective and not scientific. Interpersonal comparisons of utility are value judgements but they shall be used for drawing advice on economic policy (Scitovsky, 1951, p. 314).

Scitovsky called for the acceptance of comparability even if it is a value judgement. He pointed out that many important elements of economics which were established as part of the economic theory were themselves value judgements. Scitovsky's example was that the preference for prosperity over depression was itself a value judgement (Scitovsky, 1951, pp. 317-8).

Similar to the position of the second group are the ideas of Rawls. In particular, Rawls doubted the scientific status of interpersonal comparisons, but he accepted their value as moral or political principles (Rawls, 1958, p. 191). In his later work, A Theory of Justice, Rawls identifies the need to find some objective grounds of 
comparability for questions of social justice. His suggestion is to identify first the least advantaged person in the community, and then to see whether a change in the basic structure makes him better or worse off. By this method we can determine the best situation. Thus:

While qualitative interpersonal comparisons are made in finding the bottom position, for the rest ordinal judgements of one representative man suffice (Rawls, 1971, pp. 71-2).

Rawls' basis for comparability is not utilitarian oriented. The above principle which is called the difference principle was to give new interest to the issue. Rawls' approach was to be used for constructing Rawlsian social welfare functions.

Atkinson and Stiglitz's approach to the issue can also be seen as belonging to the second group. More specifically, Atkinson and Stiglitz's views concentrate on the connection of comparability with the theory of taxation. In their work they admit that the "New Welfare Economics" (the positivist position) does not provide sufficient guidance for public policy suggestions and they proceed to accept comparability explicitly (Atkinson and Stiglitz, 1980, p. 352). Apart from the above, Atkinson and Stiglitz (in the process of building a taxation theory) use social welfare functions despite Arrow's theorem (Atkinson and Stiglitz, 1980 part B). Since Atkinson and Stiglitz's Lectures on Public Economics has been very influential, the position of the second group on the issue of comparability would seem to have significance among contemporary theorists.

\section{Third Group}

The third group's position on comparability can be seen as closer to the utilitarian approach, since interpersonal comparisons are basically regarded as scientifically sound. Economists whose ideas on comparability belong to this group were mainly influenced by Marshall's and Pigou's approach to the issue. Their first step towards the reinstatement of comparability was the reintroduction of cardinal utility. We have stated that in the first decades of this century cardinal utility started to be replaced by ordinal utility (the first attempt was carried out by Pareto). In practice, the welfare theorists after Robbins, who rejected comparability, thought of utility as an ordinal concept. However, in the 1950s there were signs of a revival of the 
old conception of utility as cardinally measurable.

More specifically, in 1952 in an article entitled "A Cardinal Concept of Welfare", Fleming attempted to reintroduce cardinality into welfare economics. Fleming's method was to set five ethical postulates which are necessary for establishing the cardinality of welfare. These postulates "will suffice to ensure that the welfare concept characteristic of that ethical system will be susceptible to fundamental measurement" (Fleming, 1952, p. 369). Although Fleming does not explicitly refer to the issue of comparability, it is obvious that cardinality facilitates to a great extent the conception of interpersonal comparisons as scientific.

The discussion of cardinal welfare continued in the work of Harsanyi. Harsanyi finds that Fleming's postulates are value judgements, but that they are perfectly acceptable according to common ethical standards. So, he holds that the concept of additive cardinal welfare is a logical one. Along with cardinality, Harsanyi accepts interpersonal comparisons too. In a statement which echoes Marshall and Pigou, Harsanyi holds that:

In the case of persons with similar preferences and expressive reactions we are fully entitled to assume that they derive the same utilities from similar situations (Harsanyi, 1955, p. 317).

After this acceptance of comparability, he refers to the positive-based view of the first group, that interpersonal comparisons are value judgements and unacceptable for economic policy. In a manner which reflects the spirit of the third group, he states that comparability is a factual proposition based on certain principles of inductive logic, and it can be objective depending on the extent of the factual (psychological) information (Harsanyi, 1955, pp. 320-1).

Robertson's ideas about comparability reflect more explicitly the uneasiness of some economists with the inconsistency between theory and practice. Robertson emphasises that by cardinal utility and interpersonal comparisons of utility we can draw inferences about important matters such as taxation policy (Robertson, 1954, p. 38). His main point is that the tools of a measurable utility and of comparability can help us proceed with economic problems which are crucial to society.

Little can be viewed as another influential theorist whose ideas on comparability 
belong to the third group. Little rejected the conception of comparability as a value judgement and states that interpersonal comparisons rest on observations or introspection and therefore they are empirical judgements about the real world (Little, 1973, pp. 56,66).

The position of the third group on comparability emerged in the 1950s as a reaction to the positivism of the first group. However, apart from the above works which were published during that period, the third group's approach can be recognised in the writings of subsequent theorists. Sen, for instance, points out that his attitude towards interpersonal comparisons "involves neither Pigovian precision, nor Robbinsonian rejection" (Sen, 1982, p. 23). He openly condemns the idea that comparability should be rejected. In his work (and especially in his intersection approach) Sen allows partial interpersonal comparability, which means "that utility comparisons may be neither impossible nor — on the other hand - terribly exact" (Sen, 1982, p. 22).

Analogous to Sen is Ng's view which can be found in his Welfare Economics. $\mathrm{Ng}$ admits the practical difficulties of cardinal utility but he holds that individual utility is cardinally measurable $(\mathrm{Ng}, 1979, \mathrm{p} .17)$. This leads to a similar position on comparability, very close to those accepting interpersonal comparison as perfectly legitimate:

Judgements involving interpersonal comparisons of utility are subjective judgements of fact. Even though the facts are of a subjective nature, it is very difficult to measure individual utilities and to compare them interpersonally with any degree of precision. While such difficulties should not be underestimated, they do not make interpersonal comparison value judgements (Ng, 1979,p. 15).

$\mathrm{Ng}$ 's position is close to Harsanyi's factual assumption approach. $\mathrm{Ng}$ represents the conception of an acceptable but imprecise comparability.

Other advocates of the third group position are even closer to utilitarian acceptability. For instance, Jeffrey proposes to use Bentham's normative political theory together with a utility concept based on the work of von Neumann and Morgenstern. Von Neumann and Morgenstern had made attempts towards a numerical concept of utility based on probability theory (von Neumann and Morgenstern, 1953, p. 24). According to this view this would lead to a substitution 
of interpersonal comparisons of utilities with the interpersonal comparisons of preferences Geffrey, 1971, pp. 647-56). It is clear that Jeffrey attempts to avoid the ambiguity of the concept of utility. In its place the more "objective" concept of preferences is used. However, it seems that this approach does not have much influence.

Simon's view is also closely associated with utilitarianism. Simon holds that in order to avoid fruitless metaphysical discussions about utility and interpersonal comparisons, economists should choose that proxy or proxies which seem best to stand for the underlying concept and are measurable (Simon, 1974, p. 82). Analogous to Simon is Hammond's view which sees nothing illegitimate in accepting dual comparability: comparability of utility levels and utility differences or both (Hammond, 1977).

These, then, were the main representatives of the viewpoints of the three groups identified above. Chronologically, up to the beginning of the 1970s the issue of comparability was considered by the great majority of economists as settled.

Despite the appearance of works which condemned a strict positivist approach to the issue, the norm was that interpersonal comparisons are not scientific and that they are not legitimate for economic policy recommendations. However, since that period discussions about comparability have appeared again and this was due to the increasing influence of the second and third groups' viewpoints. In addition to that, however, the established practice of policies which presuppose comparability made the limitations of a positivist theoretical approach to the issue quite clear.

The result was that an increasing number of welfare economics theorists seem to be sympathetic to some form of acceptance of comparability (second and third groups). The important implication of this is that recently the strict positivist position (First group) has started to be undermined. However, it must be noted that the positivist viewpoint is still very strong among non-specialists.

\section{Conclusion}

The starting-point of this article was the inconsistency between the established 
practice of accepting comparability in many cases of economic policy and the theoretical rejection of interpersonal comparisons by the majority of economists. In particular, it was noted that a great number of economists conceive interpersonal comparisons as a value judgement and thus non-scientific, On the other hand it was observed that comparability is implicitly accepted in many cases as for instance in progressive taxation, national insurance policies and in the very notion of aggregate real income as a welfare indicator.

This inconsistency was explained with a historical discussion of the development of the different viewpoints on the issue. This enabled an identification of two broadly defined approaches: the utilitarian one (cardinality and acceptance of comparability) and the positivist one (ordinal utility and rejection of comparability) as unscientific. After Robbins the approaches to the issue became more refined. In particular, three broadly defined groups were identified. The first group was made up by those who thought of comparability as a value judgement and unacceptable for economic policy recommendations. This group can be termed "positivist" since it can be seen as a continuation of the positivist tradition of Pareto. The second group was composed of those who agreed with the positivists on the normative nature of comparability but accepted it was a basis for economic policy. Finally, advocates of the third group thought of comparability as part of a scientific economics. Clearly this group is close to the utilitarian approach to the issue seen in the first part of the article.

The above enabled the observation that, despite the numerous attempts by positivist oriented economists to dismiss interpersonal comparisons as unscientific, a strong tendency by many economists to ignore the positivist limitations exists. Thus, although positivism is still a dominant methodological position and it is followed in other sub-fields (i.e. consumer theory), the historical experience points to the difficulty of applying positivist methodology to the issue of comparability. All these indicate that the problem of interpersonal comparisons has important implications for the positivist methodology: one might question the validity of a methodology which cannot be applied universally. A general assessment of this point, however, is beyond the scope of this article. 
Nevertheless, one can draw some observations regarding the issue of positivenormative distinction which is an important part of the positivist approach. More specifically, given the above, one might adopt Myrdal's complete denial of the possibility of such distinction in economics or Hutchison's moderate thesis (see Myrdal, 1953; Hutchison, 1964). However, the case of interpersonal comparisons is a clear example where the positivist methodology, and especially the positivenormative distinction, is highly problematic. Thus, it can be maintained that the inconsistency between the established practice of implicitly accepting comparability and its explicit theoretical rejection is due to the inappropriateness of the positivist approach in the social context.

The recent trend towards a compromise has not been able to introduce a satisfactory solution, and comparability remains a highly problematic issue. It seems that the only way towards a solution would be to abandon fully and explicitly the positivist principles at least in matters related to the collective aspects of economics. 


\section{References}

Aron, R. (1967), Main Currents in Sociological Thought, Penguin, London.

Arrow, J.K. (1963), Social Choice and Individual Values, John Wiley and Sons, New York.

Atkinson, A. and Stiglitz, J.E. (1980), Lectures on Public Economics, McGraw-Hill, London.

Bentham, J. (1882), Theory of Legislation, Trubner and Co., London.

Bentham, J. (1969), in Mack, M.P. (Ed.), A Bentham Reader, Pegasus, New York.

Bergson, A. (1938), "A Reformulation of Certain Aspects of Welfare Economics",

Quarterly Journalof Economics, Vol. 52, pp. 310-34.

Blum, W. and Kalven, H. (1953), The Uneasy Case for Progressive Taxation,

University of Chicago Press, Chicago.

Carnap, R. (1981), "Protocol Statements and the Formal Mode of Speech", in

Hanfling, 0. (Ed.),Logical Positivism, Basil Blackwell, Oxford.

Cooter, R. and Rappoport, P. (1984), "Were the Ordinalists Wrong about Welfare

Economics?",Journal of Economic Literature, Vol. 22, pp. 507-30.

Creedy, J. (1981), "F.Y. Edgeworth", in O'Brien, D.P. and Presley, J. (Eds.), Pioneers of Modern Economics in Britain, Macmillan, London.

Edgeworth, F.Y. (1881), Mathematical Psychics, Kegan Paul, London.

Edgeworth, F.Y. (1925), Papers Relating to Political Economy, Macmillan, London.

Fisher, I. (1927), "A Statistical Method for Measuring Marginal Utility", in Hollander,

J.H. (Ed.),Economic Essays in Honor of J.B. Clark, Macmillan, New York.

Fleming, M.(1952), "A Cardinal Concept of Welfare", Quarterly Journal of

Economics, Vol. 66, pp.366-84.

Hammond, P. (1977), "Dual Interpersonal Comparison of Utility and the Welfare

Economics of Income Distribution", Journal of Public Economics, Vol. 7, pp. 51-71.

Harrod, R.E. (1938), "Scope and Method of Economics", The Economic Journal, Vol. 48, pp. 383-412.

Harsanyi, J. (1955), "Cardinal Welfare, Individualistic Ethics and Interpersonal

Comparisons of Utility", Journal of Political Economy, Vol. 63, pp. 309-21.

Henderson, J. and Quandt, R. (1971), Microeconomic Theory, McGraw-Hill, New York. 
Hicks, J. (1939), "The Foundations of Welfare Economics", The Economic Journal, Vol. 49, pp. 696-712.

Hicks, J. and Allen, R.G.D. (1934), "A Reconsideration of the Theory of Value", Economica, Vol.1, pp. 52-76.

Hutchison, T.W. (1953), A Review of Economic Doctrines, Clarendon Press, Oxford.

Hutchison, T.W. (1960), "Positive" Economics and Policy Objectives, Allen \& Unwin, London.

Hutchison, T.W. (1965), The Significance and Basic Postulates of Economic Theory, Augustus M. Kelly, New York.

Jeffrey, R. (1971), "On Interpersonal Utility Theory", Journal of Philosophy, Vol. 68, pp. 647-56.

Jerons, W.S.(1871), The Theory of Political Economy, Macmillan, London

Kaldor, N. (1939), "Welfare Propositions of Economics", The Economic Journal, Vol. 49 , pp. 549-52.

Koutsoyiannis, A. (1979), Modern Microeconomics, Macmillan, London.

Lange, 0. (1942), "The Foundations of Welfare Economics", Econometrica, Vol. 3 No. 4, pp. 215-28.

Little, I.M.D. (1973), A Critique of Welfare Economics, Oxford University Press, London.

Marshall, A. (1961), Principles of Economics, 9th edition, Macmillan, London.

Mill, J.S. (1979), in Warnock, M. (Ed.), Utilitarianism, Collins, Glasgow.

Myrdal, G. (1953), The Political Element in the Development of Economic Theory,

Routledge \& Kegan Paul, London.

Neumann, von J., and Morgenstern, 0.(1953), Theory of Games and Economic

Behaviour, Princeton University Press, Princeton.

Ng, Y-K. (1979), Welfare Economics, Macmillan, London.

Pareto, V. (1896), Cours d'Economie Politique, E. Lange, Lausanne.

Pareto, V. (1971), Manual of Political Economy, translated by Schrier, A., Macmillan, London.

Pigou, A.C. (1932), The Economics of Welfare, Macmillan, London.

Pigou, A.C. (1951), "Some Aspects of Welfare Economics", The American Economic Review, Vol. 41, pp. 287-302.

Rawls, J. (1958), "Justice as Fairness", The Philosophical Review, Vol. 67, pp. 16474. 
Rawls, J. (1971), A Theory of Justice, Harvard University Press, Cambridge, Mass.

Robertson, D.H. (1954), Utility and All That, Allen \& Unwin, London.

Robbins, L. (1938), "Interpersonal Comparisons of Utility: A Comment", The

Economic Journal,Vol. 48, pp. 635-41.

Robbins, L. (1969), An Essay on the Nature and Significance of Economic Science,

Macmillan, London.

Samuelson, P. (1947), Foundations of Economic Analysis, Harvard University Press, Cambridge,Mass.

Scitovsky, T. (1951), "The State of Welfare Economics", American Economic

Revieiv, Vol. 41, pp.303-15.

Sen, A. (1970), Collective Choice and Social Welfare, Holden-Day, Oliver and Boyd, San Francisco.

Sen, A. (1982), Choice, Welfare and Measurement, The MIT Press, Cambridge, Mass.

Simon, J. (1974), "Interpersonal Welfare Comparisons can be Made and Used for Redistribution Decisions", Kyklos, Vol. XXVII, pp. 63-98.

Stigler, G. (1950), "The Development of Utility Theory", Journal of Political Economy, Vol. 58, pp. 307-27.

Tarascio, V. (1979), "Vilfredo Pareto and Marginalism", History of Political Economy, Vol. 4, pp. 406-25.

Usher, D. (1980), The Measurement of Economic Growth, Blackwell, Oxford. Wicksell, K. (1961), Lectures on Political Economy, translated by Classen, E., Routledge \& Kegan Paul, London.

Wicksteed, P. (1933), The Common Sense of Political Economy, Routledge \& Kegan Paul, London. 